Article

\title{
Religious Hallucinations and Religious Delusions among Older Adults in Treatment for Psychoses in the Netherlands
}

\author{
Annemarie Noort ${ }^{1,2, *}$, Aartjan T. F. Beekman ${ }^{2}$ and Arjan W. Braam ${ }^{3,4}$ \\ 1 Independent Practice for Psychiatry, Centre for Geriatric Psychiatry, 3502 MA Utrecht, The Netherlands \\ 2 Department of Psychiatry, Vrije University Medical Centre (VUmc), 1105 AZ Amsterdam, The Netherlands; \\ a.beekman@ggzingeest.nl \\ 3 Department of Emergency Psychiatry and Department of Residency Training, Altrecht Mental Health Care, \\ 3512 PG Utrecht, The Netherlands; a.braam@altrecht.nl \\ 4 Department of Humanist Chaplaincy Studies for a Plural Society, University of Humanistic Studies, \\ 3512 HD Utrecht, The Netherlands \\ * Correspondence: mailcuran@gmail.com
}

Received: 7 September 2020; Accepted: 6 October 2020; Published: 12 October 2020

\begin{abstract}
Background. Although religious delusions (RDs) are common in geriatric psychiatry, we know little about their frequency and content. Our study examines the prevalence and content of religious hallucinations (RHs) and RDs and how they relate to the diagnosis and the patients' denominational background and other aspects of religiousness. Methods. Semi-structured diagnostic interviews were conducted with inpatients and outpatients $(\mathrm{N}=155$, mean age 76.5$)$ at a geriatric psychiatry department in the Netherlands. We used the Schedules for Clinical Assessment in Neuropsychiatry 2.1. Results. The prevalences of RHs and RDs were $19 \%$ and $32 \%$, respectively. RHs were mostly auditory. There was no statistically significant difference between the prevalence of RHs in schizophrenia (17.5\%) and in psychotic depression $(9.4 \%)$. Compared to non-affiliated patients and mainline Protestants, RDs were significantly more prevalent in raised and current strict Protestants, especially in those with psychotic depression. RHs were more prevalent in Evangelical (e.g., Pentecostal) and strict Protestant patients. The presence of RDs was associated with several measures of religiousness (e.g., dogmatism, religious coping). Conclusions. Religion is likely to act as a symptom-formation factor for psychotic symptoms in strict Protestant older adults. More detailed research might lead to a fuller understanding of how strict religious beliefs may affect the content of psychotic symptoms and unintentionally add a component of existential suffering. It is important for mental health professionals, especially the predominantly secular professionals in the Netherlands, to recognize and address religious themes.
\end{abstract}

Keywords: religious hallucination; religious delusion; psychosis; schizophrenia; psychotic depression; old age; older adults; religiousness; religious coping

\section{Introduction}

Although religious delusions (RDs) and religious hallucinations (RHs) may be common and important features of psychosis, little is known about their prevalence and content and how they are related to affective or non-affective psychoses. In his review of 55 quantitative empirical studies on RDs and RHs, Cook (2015) noted that the lack of critical criteria for defining and classifying them makes comparison difficult. In addition, their prevalence clearly varies with time and place, and probably also with personal religiousness. 
Hallucinations can be a core symptom of schizophrenia, schizo-affective disorder, and affective psychoses (depression, mania) (Galleti et al. 2017; Lim et al. 2016; Okutate and Jones 2003). In an overview study on schizophrenia inpatients and outpatients, Waters et al. (2014) observed a mean prevalence of auditory hallucinations of 59\% (range 25-86\%) and of visual hallucinations of $27 \%$ (range 4-65\%). The wide variation in prevalences is likely to reflect variations in sample types and measurement methods. Overall, the most common hallucinations are auditory (Bauer et al. 2011; Mbewe et al. 2006; Peralta and Cuesta 1999), followed by visual, somatic, and other hallucinations (Rajapakse et al. 2011; Bauer et al. 2011; Chaudhury 2010; Thomas et al. 2007).

The expression of psychiatric symptomatology is likely to depend on cultural and religious beliefs (Azhar et al. 1993; Gecici et al. 2010). Kent and Wahass (1996) investigated the content of auditory hallucinations reported by 75 adult schizophrenia inpatients and outpatients in Saudi Arabia and the United Kingdom. Auditory hallucinations with religious themes (second- or third-person voices) occurred significantly more frequently in Saudi (33\% and 53\%) than in UK patients (6\% and $11 \%)$. Gecici et al. (2010) described the content of hallucinations in a sample of 373 schizophrenia inpatients in Turkey. Patients in central Turkey, where religion is generally an important element of public and private life, report significantly higher rates of RHs (about 6\%) than patients in the more secularized western part of Turkey (about $2 \%$ ).

In a 22-year retrospective analysis of the changing frequency and patterns of religious symptoms in Egyptian inpatients with psychotic illness (affective and non-affective, $\mathrm{N}=913$ ), Atallah et al. (2001) described significant changes in RHs over time. In 1987 to 1988, the prevalence of auditory and visual RHs was $15 \%$ and $10 \%$, and in 1989 to 1990 it was 35\% and $21 \%$, largely as a result of the fluctuating political and religious climate in Egypt. Muslim and Christian patients exhibited similar rates of RHs.

The prevalences of RHs and RDs also vary between episodes of a disorder. In a cross-sectional study on the prevalence of religious and spiritual experiences in bipolar outpatients $(\mathrm{N}=196$, mean age $=46)$, $4 \%$ of the patients in the manic episode and $0 \%$ of those in the depressive episode ever heard a divine voice speak to them. The sense of being an important religious person was prevalent in $17 \%$ of the patients in the manic episode and 1\% of those in the depressive episode (Ouwehand et al. 2019).

Religion and spirituality play a significant role in the lives of many individuals, including those with a psychotic disorder (Grover et al. 2014). Religion may influence the expression of psychopathology. This is why it is so important to make clinicians aware of how religious beliefs can play a role in psychotic symptomatology. To a certain extent, religious beliefs may have a supportive effect, but RDs and RHs can also reflect or provoke a sense of existential suffering. It is important for mental health professionals to recognize and address religious themes in the diagnostic and therapeutic dialogue. This can make the patient feel better understood and benefit the therapeutic relationship. In the Netherlands, most of the older generation was brought up within a religious tradition.

The present study was conducted in the Dutch Bible Belt, a region with multifarious religious denominations ranging from mainstream and strict Protestants with substantial pietistic and dogmatic Reformed minorities to Roman Catholics or Evangelicals, including Pentecostal communities. Even in the Dutch Bible Belt, many people are unaffiliated. The strict Protestant traditions include the dogmatic segment of Reformed Protestantism as well as the "devotion" groups (Hoekstra and Ipenburg 1995). Dogmatism is conceived of as a rational approach to faith with an emphasis on endorsing its virtues. The strict Protestants are very loyal to the Reformed Bible interpretation and Reformed confessions (De Jong 2012). In addition, another important characteristic is the emphasis on finding "the way of repentance" (Hijweege 2004). Strict Protestants include the Reformed Congregations, Reformed Bond, Reformed Congregations in the Netherlands, Restored Reformed Church, Christian Reformed Church, and the Old-Reformed Congregations in the Netherlands. In a qualitative study among pietistic Reformed protestants, Hijweege characterized how people in pietistic Reformed churches find themselves "placed in relation to an almighty God who may or may not intervene in their lives, but Who certainly will judge their individual way of life" (Hijweege 2004, pp. 116-17). According to Hijweege, this position may evoke feelings like anxiety or despair. A community-based study among older adults in the Netherlands 
suggests higher levels of depressive symptoms in older adults living in villages with a predominantly pietistic Reformed religious climate (Braam et al. 1999). In a lifetime, one can worry about the question whether one will inherit eternal life or will be eternally lost. Since this is not underpinned by an active act of the believer and being born again is only a grace of God, it is conceivable that these beliefs can lead to depressive symptoms and anxiety, and perhaps even psychopathology.

There are empirical indications that the depression rates in these communities are twice as high as in other rural communities (Braam et al. 2001). Moreover, one might wonder whether dogmatism leads to a higher prevalence of RDs in strict Protestant psychotic patients than in patients from other denominations. Furthermore, strict Protestant patients are at risk of under-diagnosis and under-treatment (De Lely et al. 2009). It is possible that the emphasis on devotion during a psychotic disorder in strict Protestant patients causes a higher prevalence of RDs than in psychotic patients from other denominations.

One might also wonder whether religion-related symptom-formation effects on the contents of RDs and RHs differ for affective and non-affective psychoses. Here, the question is how delusions arise in general and RDs in particular. Several processes probably play a role in the formation of delusions (Rieben et al. 2013; Mohr et al. 2009). Delusions can serve as an explanation for abnormal observations such as voices. In states of psychotic anguish, the delusion can serve as psychological protection to help a patient understand a confusing experience. Delusions can also arise directly from reasoning errors, with various types of thinking errors contributing to beliefs that are beyond comprehension to outsiders. In schizophrenia, for example, although the ultimate cognitive experiences underlying delusions remain the subjecture, it is clear that there are reasoning errors that accompany delusion formation in schizophrenia. When tested, people with schizophrenia who have delusions will make decisions based on less information than people with schizophrenia and no delusions, or compared to normal populations (Lewis et al. 2017). These explanations can be assumed to differ for affective and non-affective psychoses. In psychotic depressive disorders, negative thinking acquires grossly delusional proportions and is maintained with such conviction that the thoughts are not amenable to the change by evidence to the contrary. Thus, severely depressed patients may have delusions of worthlessness and sinfulness (Akiskal 2017), which can develop into RDs. The person's religious background or other aspects of religiousness can affect the type and content of delusions and hallucinations in late-life psychoses. We formulate the following three research questions.

Research Question 1. In addition to what is known about the prevalence of RDs in psychotic patients in later life (Noort et al. 2018), what are the prevalence and content of RHs in older psychotic patients?

Research Question 2. How do RDs and RHs relate to the main diagnosis?

Research Question 3. How do RDs and RHs relate to denominational background and do possible associations depend on the main diagnosis (affective vs. non-affective psychosis)?

Research Question 4. How do other aspects of religiousness relate to RDs and RHs?

\section{Method}

\subsection{Subjects}

The study was conducted from 2005 to 2011 at the Geriatric Psychiatry Department of Yulius, a mental health care organization serving the Gorinchem and Dordrecht region in the Netherlands. Processing the data was delayed due to other ongoing research/personal circumstances. Outpatients and inpatients were recruited by their clinicians. The study was approved by the Medical Ethical Committee of the Vrije Universiteit Medical Centre Amsterdam. The patients in the study were above the age of 65 and they had been clinically diagnosed with schizophrenia (295), schizophreniform disorder (295.40), schizoaffective disorder (295.70), delusional disorder (297.1), brief psychotic disorder (298.8), psychotic disorder not otherwise specified (298.9), severe depressive disorder with psychotic features (296. $\times 4$ ), and severe bipolar disorder, manic, mixed or depressed, with psychotic features $(296.44,296.54,296.64$ and 296.89), according to the Diagnostic and Statistical Manual (DSM) 4th edition of the American Psychiatric Association (American Psychiatric Association (APA) 2000). In the Netherlands, classifying according to 
DSM is part of the regular mental health care practice. The participants also took part in a systematic diagnostic interview, the Schedules for Clinical Assessment in Neuropsychiatry (SCAN 2.1, see below; Giel and Nienhuis 2001), which provided the diagnostic information for the aims of the present study.

The exclusion criteria were psychotic disorders due to a somatic condition, (probable) severe neurocognitive disorder (dementia), delirium, substance-related mental disorders, personality disorders as primary diagnosis, as well as psychotic experiences due to dissociative symptomatology. In case of a score of 17 points or less on the Standardized Mini-Mental State Examination (MMSE, Folstein et al. 1975), possible underlying causes of cognitive dysfunction were evaluated. In the event of (probable) dementia, the patient was excluded from the study.

\subsection{Procedures}

First, all the patients already under treatment who fulfilled the inclusion criteria (including ten patients with a bipolar II disorder with a psychotic depressive state) were liable to be included $(\mathrm{N}=77)$ and could be included in the following five years. Second, newly referred patients in the Geriatric Psychiatry Department $(\mathrm{N}=168$, including eight with depressed bipolar II disorder with psychotic symptoms) could be included as well.

After informed consent was obtained, psychotic phenomena, RDs and RHs in particular, were assessed as specifically as possible using the SCAN 2.1 Giel and Nienhuis 2001). The SCAN was developed by the WHO and replaced the Present State Examination (Wing et al. 1989). Ten sections were administered: Section 1 (start of the interview), Sections 3, 6, 7 and 8 (in depressed mood), Section 10 (in manic mood), and Sections 17-20 (psychotic symptoms). The computerized algorithm of the SCAN 2.1 (WHO-SCAN for Windows, Dutch full version v.1.0.4.6, Harcourt, Lisse, The Netherlands) provided DSM-IV diagnoses (The SCAN interview applies clear criteria to ascertain a delusion and requires that the delusional belief should be clearly recorded (1) in the participant's own words, (2) it is a fundamental and irresistible, subjective conviction; (3) the belief is not—or only briefly-susceptible to change based on experience or evidence to the contrary, in other words, the belief is un-correctable, and (4) the belief is impossible, implausible or false. All possible delusions are questioned, after which the question is asked about religious statements: What is the explanation for this/your experiences? Is there a religious explanation for it? However, beliefs that are shared and fully explained by certain religious (or political or other social groups) are not delusions. When possible RDs were identified with the SCAN interview, the interviewer made detailed notes about the contents of the (probably delusional) conviction or experiences. Afterwards, when elaborating on the entire interview, the interviewer (first author, who is familiar with orthodox Protestant convictions) evaluated whether the convictions or experiences could be understood as belonging to strict orthodox convictions or (for other denominations) as belonging to more or less normal, non-pathological spiritual experiences. Spiritual experiences such as "oceanic feelings" or "feelings of unity" have not been interpreted psychiatrically. Occult and telepathy is not counted in the SCAN as a religious delusion, but as "paranormal." Here, the main interviewer (AN) was able to verify non-pathological strict Protestant convictions as she is familiar with orthodox Protestantism in the Netherlands. Hallucinations like those derived from SCAN items are non-verbal auditory hallucinations (17.003), frequency verbal auditory hallucinations (17.004), voices commenting on or talking about the patient (17.008), shapeless visual hallucinations (17.015), shaped visual hallucinations (17.016), hallucinated scenes (17.017), olfactory hallucinations (17.022), hallucinations that the patient is spreading an odor (17.024), sexual hallucinations (17.026), hallucinations of other senses (17.028), apparent hallucinatory experiences, unspecified (including occult or inexplicable experiences not shared by a sect, etc.) (17.030). Scores on 17.004 were recoded into 1 (rarely-usually always) or 0 (other scores), and on 17.008 they were recoded into 1 (voices commenting, repeating, or describing) or 0 (other scores). All the other scores on hallucinations were recoded into 1 (certainly or more or less constantly) or 0 (other scores). Like delusional beliefs, hallucinations were also clearly recorded in the respondent's own words. As there is no separate question in the SCAN about hallucinations with religious content, all the data were manually investigated, and each RH was counted and described by content. 


\subsection{Other Variables}

Since religiousness was approached as a multidimensional construct, multiple scales and items were used. First, religious affiliation. Four categories were used corresponding with the main Christian traditions in the Netherlands, i.e., mainline Protestant (Dutch Reformed or Liberal), dogmatic/pietistic Protestant or strict Protestant such as Pietistic Reformed or other Reformed (devout) denominations, Roman Catholic and Evangelical, e.g., Pentecostal. The patients were asked which church they belonged to and which church they were raised in. Second, the degree of dogmatism defined as the level of adherence to traditional (Christian) religious beliefs was assessed by the Orthodoxy Scale, which was regularly used in studies by the Dutch Social and Cultural Planning Office (Becker and Vink 1994). The term orthodoxy has multiple meanings. Here, two meanings are important to distinguish. First, in Protestant churches it has a mainly cognitive meaning (the straight or pure doctrine; strict adherence to church doctrine). Second, the other meaning of Orthodoxy (Doxa-(Gr.), Gloria, Glory) is about "proper praise," and relates to the liturgy. The orthodox scale concerns cognitive religious doctrines. For that reason, the word dogmatism is more appropriate and applied to paper. The doctrines included were ("Do you believe in ... ?") life after death, heaven, purgatory, hell, the devil, the actual existence of Adam and Eve, and the Bible as God's word. The answers were $1=$ yes, $2=$ no, $3=I^{\prime} \mathrm{m}$ not sure, recoded in $1=2$ (yes), $3=1$ (I'm not sure), or $2=1$ (no), yielding a total score range of 0 to 14 . Cronbach's alpha was 0.87. Third, the salience or subjective importance of faith (Hoge and de Zulueta 1985; Braam et al. 1997) was assessed with eight questions about the three most important aspects of life (a good income, a harmonious family, good health, meaningful pastimes, a good marital life, a strong faith, many friends and acquaintances, good housing). If $a$ strong faith was circled, religion was considered salient. Fourth, frequency of church attendance was assessed using response categories from $1=$ once a year or less to $5=$ once a week or more, and recoded in $0=$ less than once a month or never, or $1=$ once a month or more. Fifth, frequency of prayer was assessed using the question: "How often do you pray or meditate?" with response categories from $1=$ never to $7=$ more than once a day, and recoded in $0=$ never pray to less than daily or 1 = pray daily of more. Sixth, in strict Protestants, $a$ strong faith is not something within one's own capacity (Hijweege 2004). So we added the question, "Do you believe you are a child of God?" The response categories $0=$ no, $1=$ sometimes or $2=$ yes, were recoded as $0=$ no, $1=$ I don't know, 2 = sometimes yes, sometimes no or $3=$ yes.

Seventh, religious coping was assessed using an 11-item Dutch version of the Brief Religious Coping Scale (brief RCOPE) instead of the 14-item version, which seemed to be slightly less culture-sensitive (Pargament and Koenig 2000; Braam et al. 2008). The positive religious coping scale included five items in our study (concise content: works together with God as partners, looks to God for strength, finds support and guidance, tries to find lessons from God, confesses sins, and focuses on religion to stop worrying. Cronbach's alpha $=0.81$ ). The negative religious coping scale has four items (concise content: wonders whether one has been abandoned by God, questions whether God exists, expresses anger at God and doubts God's love. Cronbach's alpha $=0.53$ is low.) In fact, the scale is a summation of negative cognitions without common characteristics. At the time of the study, no better questionnaire was available. The response categories were $1=$ not at all, $2=$ somewhat, $3=$ quite a bit, $4=$ a great deal, and were recoded as $0=$ never or somewhat or $1=$ others. One item on the negative coping subscale pertains to punishment appraisal ("I feel stressful situations are God's way of punishing me for my sins or lack of spirituality.") As in a pilot study (Braam et al. 2008), this item did not load on the dimension of negative coping. It had a modest loading on the positive coping scale and was not used further in our study. Eighth, frequency of reading the Bible or other religious texts was assessed using the question, "How often do you read the Bible or other religious texts?" with response categories from $1=$ never reads the Bible or other religious texts to $7=$ more than once a day and recoded as $0=$ never reads the Bible or other religious texts to less than daily or $1=$ reads the Bible or other religious texts daily or more.

The demographic variables include age, gender, marital status, and years of education. Marital status was recoded as $1=$ married or living together, or $0=$ widowed, living separately, legally divorced or never married and not living together (single). 


\subsection{Data Analysis}

First, the distributions were noted for the prevalence of various types of hallucinations and/or RHs using cross-tabulations and Chi-square statistics. Second, using cross-tabulations and Chi-square statistics, the frequency was examined of RDs and RHs being related to the main diagnostic categories. To this end, the diagnostic categories schizophrenia and psychotic depression were used, because both have more specifically delineated syndromes as a result of a chronic or at least intermittent course and a considerable burden on the patient and a need for care. The number of patients with other conditions (e.g., delusional disorder and bipolar disorder) was too small to include them in meaningful analysis. Third, using logistic regression analysis, the links were analysed between types of religious denominations in the past and present and RDs and RHs. Possible links between religious denominations and RDs or RHs may depend on the diagnosis (schizophrenia or psychotic depression). The significance of the interaction terms between the denominations and the diagnostic categories was computed in the association with RDs and RHs. Next, the logistic regression analyses for denominational groups and RDs or RHs were repeated for both diagnostic groups (schizophrenia and psychotic depression). So, apart from these diagnostic categories, the phenomena of RD and RH may still be relevant in their association with religious background. Therefore, the entire dataset was utilized to analyze associations between RDs and RHs with religious background and religiousness. By way of sensitivity analysis, interaction terms between main diagnostic groups with religious denomination were explored. The level of statistical significance was set at $p<0.05$ for the main effects and the interaction effects. Fourth, to confirm finding with respect to denominational background (denominations may differ between regions, countries and continents), whereas the other variables of religiousness can be applied to any (generally Christian) population, and providing a deeper understanding about effects for denominational background, we used the same comparison method for other aspects of religiousness (dogmatism, salience, church attendance, praying, seeing oneself as a child of God, scores on the positive religious coping subscale or negative scores on the negative religious coping subscale, reading the Bible or other religious texts) as regards RDs and RHs, and logistic regression analyses were performed. Statistical analyses were conducted using IBM SPSS Statistics (version 2.1, SPSS Inc., Chicago, IL, USA).

\section{Results}

\subsection{Characteristics of the Sample}

The characteristics of the sample are shown in Table 1. The majority of the respondents were female $(72 \%)$, the mean age was 76.5 , a third lived together, and $57 \%$ were outpatient. The most common diagnoses were schizophrenia (37\%) and psychotic depression (34\%). As to patients' religion, there was considerable heterogeneity with a third mainline Protestant, a third non-affiliated, a fifth strict Protestant, and very few Roman Catholics or Evangelicals.

Table 1. Characteristics of the sample $(\mathrm{N}=155)$.

\begin{tabular}{ccc}
\hline Characteristics & $\mathbf{N}$ & $\mathbf{\%}$ \\
\hline Sex Female & 111 & 72 \\
Age (mean \pm SD), range 65-97 & $(76.5 \pm 8.2)$ & - \\
Marital status & & \\
Widowed & 60 & 39 \\
Single (divorced/never married) & 47 & 30 \\
Married/living together & 48 & 31 \\
Education (mean \pm SD), range 3-18 years, N =148 & $(8.5 \pm 2.6)$ & - \\
\hline
\end{tabular}


Table 1. Cont.

\begin{tabular}{|c|c|c|}
\hline Characteristics & $\mathbf{N}$ & $\%$ \\
\hline \multicolumn{3}{|l|}{ Religious affiliation } \\
\hline Non-affiliated & 48 & 31 \\
\hline Strict Protestant ${ }^{1}$ & 29 & 19 \\
\hline Moderate Protestant & 56 & 36 \\
\hline Roman Catholic & 13 & 8 \\
\hline Evangelical & 9 & 6 \\
\hline \multicolumn{3}{|l|}{ Setting } \\
\hline Outpatient & 88 & 57 \\
\hline Inpatient, voluntary & 50 & 32 \\
\hline Inpatient, involuntary & 17 & 11 \\
\hline \multicolumn{3}{|l|}{ Main diagnosis } \\
\hline Schizophrenia ${ }^{2}$ & 57 & 37 \\
\hline Delusional disorder & 29 & 19 \\
\hline Psychotic disorder not otherwise specified & 14 & 9 \\
\hline Depressive disorder with psychotic features & 53 & 34 \\
\hline Bipolar disorder, manic episode & 2 & 1 \\
\hline
\end{tabular}

Note: ${ }^{1}$ including Pietistic Reformed, Reformed (devout), Dogmatic and Reformed (non-devout), ${ }^{2}$ including schizophreniform disorder and schizoaffective disorder.

\subsection{Prevalence and Contents of RHs}

In our study $70 \%$ of the patients $(\mathrm{N}=109)$ had hallucinations (see Table 2 ).

Table 2. Symptoms with religious content, religious hallucinations (RHs) ( $\mathrm{N}=155)$.

\begin{tabular}{ccc}
\hline Religious Hallucinations & $\mathbf{N}$ & $\mathbf{\%}$ \\
\hline Hallucinations & & \\
Religious & 29 & 19 \\
Other & 80 & 51 \\
No & 46 & 30
\end{tabular}

Religious auditory hallucinations (often co-occurring):

Religious non-verbal auditory hallucinations ${ }^{1}(\mathrm{~N}=128) \quad 11 \quad 9$

Religious auditory hallucinations ${ }^{2}(\mathrm{~N}=127) \quad 21 \quad 17$

Religious voices that make comments ${ }^{3}(\mathrm{~N}=128) \quad 13 \quad 10$

Religious visual hallucinations, clear consciousness:

Unformed visual hallucinations ${ }^{4}(\mathrm{~N}=153) \quad 6 \quad 4$

Formed visual hallucinations ${ }^{4}(\mathrm{~N}=144) \quad 96$

Whole scene $^{4}(\mathrm{~N}=142) \quad 2 \quad 1$

Religious Olfactory ${ }^{4}(\mathrm{~N}=155) \quad 1 \quad 1$

Religious sexual hallucination ${ }^{4}(\mathrm{~N}=143) \quad-\quad$ -

Religious hallucination of another sense ${ }^{5}(\mathrm{~N}=150) \quad 9 \quad 6$

Apparent hallucinatory experiences ${ }^{6}(\mathrm{~N}=135) \quad 7 \quad 5$

Note: ${ }^{1}$ Often church music or screaming of the devil. Symptoms were definitely present, several times or for part of the time or symptom was more or less persistently present. ${ }^{2}$ Hearing voices almost every week or most days.

${ }^{3}$ Voices occasionally comment, repeat or describe or often repeat or comment on actions or thoughts. ${ }^{4}$ Symptoms definitely present, several times or for part of the time, or symptom was more or less persistently present. ${ }^{5}$ Tactile hallucinations (being touched, cold, heat, pain, etc.). ${ }^{6}$ Unexplained religious experiences that are not shared by the community respondent belongs to.

The total prevalence of auditory hallucinations was $70 \%$ and the total prevalence of visual hallucinations $43 \%$. As to RHs, 29 of the 155 patients had RHs (19\%). Twenty-seven patients had one or more auditory RHs. Fifteen of the patients with RHs had two or more auditory RHs with verbal and non-verbal content. The content of non-verbal RHs was, for example, that the devil made noise or God makes his presence known by scratching and stumbling. The content of verbal RHs was, for example, the chanting of psalms, the voice of the devil or the voice of Jesus, and the content of 
comment RHs was, for example, that the devil said the patient was lost, or the voices of the devil tried to discourage prayer.

Fifteen patients with an RH had one or more visual RHs. Visual RHs were mostly formed visual RHs $(\mathrm{N}=9$ ). Six of these patients had two or more visual RHs (unformed visual RHs, formed visual RHs and whole scenes). In the visual RHs, the content of the unformed visual RHs included, for example, ghosts sent by Satan. The content of the formed visual RHs was, for example, Satan with horns and a red tail or the devil in a chair. In a whole scene visual RH, a patient could, for example, see herself as the only one thrown into a lake of fire. According to Oyebode (Oyebode 2018), unformed visual hallucinations can be classified as elementary visual hallucinations, formed visual hallucinations as organized patterns and shapes of visual perceptions, and whole scenes as complex visual hallucinations.

A third of the patients with RHs had a hallucination of a different sensory quality (e.g., tactile). The content of an olfactory RH was, for example, the devil causing a smell that made the patient go away. The content of RHs of other senses was, for example, the devil hurting, as in the Final Judgement, or the patient feeling a black coffin around him. Lastly, the content of an apparent RH experience was, for example, a patient feeling he was stopped because he perceived an evil spirit inside himself.

\subsection{Relation between RDs and RHs and Main Diagnosis}

As was noted in a previous publication (Noort et al. 2018), 49 of the 155 psychotic patients had RDs. There was no statistically significant difference between the prevalence of RDs in patients with schizophrenia (32\%) or psychotic depression $(47 \%)\left(\chi^{2}=2.8, \mathrm{df}=1, p=0.094\right)$.

Nor was there a statistically significant difference between the prevalence of RHs in schizophrenia patients $(23 \%)$ and psychotic depression patients $(19 \%)\left(\chi^{2}=0.3, \mathrm{df}=2, p=0.612\right)$. As to the types of RHs, $23 \%$ of the schizophrenia patients had auditory RHs, as did $15 \%$ of the patients with psychotic depression, so there was no statistically significant difference $\left(\chi^{2}=1.1, \mathrm{df}=1, p=0.304\right) ; 14 \%$ of the schizophrenia patients and $9 \%$ of the psychotic depressive patients had visual RHs, so again there was no statistically significant difference $\left(\chi^{2}=0.6, \mathrm{df}=1, p=0.455\right)$.

Of the 29 patients with RHs, 26 also had RDs. Examining the content of the RHs in greater detail (despite the small numbers of respondents for each characteristic), the ones about the devil or Satan were fairly common in patients with either schizophrenia or psychotic depression (Table 3). Furthermore, there was an indication that RHs about God, Jesus, or the Holy Spirit occurred more than twice as frequently in schizophrenia patients as in psychotic depressive patients.

Table 3. Content of religious hallucinations in patients with the two most common diagnoses and their religious denominations $(\mathrm{N}=155)$.

\begin{tabular}{|c|c|c|c|c|c|c|c|}
\hline $\begin{array}{l}\text { Content } \\
\text { RHs }\end{array}$ & $\begin{array}{l}\text { Schizophrenia } 1 \\
\quad(N=15)\end{array}$ & $\begin{array}{c}\text { Psychotic } \\
\text { Depression }^{2} \\
\mathrm{~N}=10 \text { ) }\end{array}$ & $\begin{array}{c}\text { Strict } \\
\text { Protestant } \\
(\mathrm{N}=8)\end{array}$ & $\begin{array}{c}\text { Moderate } \\
\text { Protestant } \\
(\mathrm{N}=10)\end{array}$ & $\begin{array}{l}\text { Roman } \\
\text { Catholic } \\
(\mathrm{N}=1)\end{array}$ & $\begin{array}{l}\text { Evangelical } \\
\qquad(\mathrm{N}=3)\end{array}$ & $\begin{array}{l}\text { Non-Affiliated } \\
\quad(\mathbf{N}=2)\end{array}$ \\
\hline Devil $^{3}$ & 6 & 8 & 6 & 6 & - & 3 & 1 \\
\hline God $^{4}$ & 9 & 3 & - & 9 & 1 & 2 & 2 \\
\hline Ghosts ${ }^{5}$ & 2 & - & - & 1 & - & 1 & - \\
\hline Others ${ }^{6}$ & 5 & 2 & 3 & 5 & 1 & - & 4 \\
\hline
\end{tabular}

Note: ${ }^{1}$ schizophrenia including delusion disorder $(\mathrm{N}=2),{ }^{2}$ psychotic depression including depressive episode in a schizoaffective disorder $(\mathrm{N}=1)$ and psychotic depression in a bipolar I disorder $(\mathrm{N}=1),{ }^{3}$ the Devil, Satan, Evil Powers, ${ }^{4}$ God, Jesus, The Lord, The Holy Spirit, ${ }^{5}$ Ghosts or Spirits, ${ }^{6}$ hears voices of believers, church hymns and praying of believers, voices of Jomanda, psalms, singing, sees ghosts of ten thousand deceased souls, lake of fire, religious music, angels with the head of mother, is in hell.

The following quotes illustrate the stereotypes on how RDs and RHs manifest themselves in the main diagnostic groups. A 91-year-old woman with a psychotic depression, raised in the strict Protestant church and still a member there, said, "The devil tells me I will not enter Heaven. He speaks in a loud voice and makes a lot of noise. I have not raised my children properly and that is why my sins will not be forgiven. There is no reason for me to drink anything anymore, as I will die and will not be pardoned." A 66-year-old man diagnosed with schizophrenia, raised in the strict Protestant 
church and currently in a moderate Protestant church, said, "My writing has been taken over by Jesus. I write things down and later on I am amazed! I could never have written these things by myself." The interviewer (AN) was allowed to look at the text but the handwriting was completely illegible.

\subsection{RDs and RHs, Denominational Background and Diagnosis}

Raised and current strict Protestant and Roman Catholic patients had RDs significantly more frequently than the other categories (see the left panel of Table 4). A strict Protestant background showed a significant interaction with the main diagnostic group (schizophrenia $(\mathrm{N}=57)$ or psychotic depression $(\mathrm{N}=53)$ ) in the association with RDs. This was apparent in patients raised in a strict Protestant denomination (product term with diagnostic group $(\mathrm{B}=2.8, \mathrm{SE}=1.1, p=0.015 ; \mathrm{N}=106$ ) as well as those currently in a strict Protestant denomination $(\mathrm{B}=-3.1, \mathrm{SE}=1.4, p=0.043 ; \mathrm{N}=110)$. Stratified analyses showed that, compared to other denominational groups, RDs were significantly more prevalent in raised strict Protestant patients with a psychotic depression $\left(\chi^{2}=14.9, \mathrm{df}=4\right.$, $p=0.005)$ than in patients with schizophrenia $\left(\chi^{2}=1.2, \mathrm{df}=4, p=0.870\right)$. Similarly, RDs in current strict Protestant patients were significantly more prevalent in patients with a psychotic depression $\left(\chi^{2}=17.4, \mathrm{df}=4, p=0.002\right)$ than in current strict Protestant patients with schizophrenia $\left(\chi^{2}=2.2\right.$, $\mathrm{df}=4, p=0.701)$.

Table 4. Associations between religious denominations (raised and present) and RDs and RHs in a sample of 155 patients; results from separate logistic regression analyses for each aspect of religious denomination, adjusted for effect by gender.

\begin{tabular}{|c|c|c|c|c|c|c|}
\hline \multirow{2}{*}{ Denomination } & \multicolumn{3}{|c|}{ Religious Delusions } & \multicolumn{3}{|c|}{ Religious Hallucinations } \\
\hline & Wald & $p$ & OR (95\% CI) & Wald & $p$ & OR $(95 \%$ CI $)$ \\
\hline \multicolumn{7}{|c|}{ Raised in religious denomination ${ }^{1}$} \\
\hline Moderate Protestant & 1.7 & 0.195 & $2.83(0.59-13.67)$ & 0.0 & 0.947 & $0.95(0.24-3.84)$ \\
\hline Strict Protestant & 9.7 & 0.002 & $14.16(2.67-75.07)$ & 1.5 & 0.221 & $2.51(0.58-10.91)$ \\
\hline Roman Catholic & 3.9 & 0.049 & $5.95(1.01-35.22)$ & 0.2 & 0.691 & $0.67(0.10-4.67)$ \\
\hline Evangelical & 0.5 & 0.462 & $2.73(0.19-39.78)$ & 0.1 & 0.755 & $1.50(0.12-19.35)$ \\
\hline \multicolumn{7}{|c|}{ Current religious denomination ${ }^{2}$} \\
\hline Moderate Protestant & 2.8 & 0.091 & $2.48(0.86-7.10)$ & 2.3 & 0.133 & $2.45(0.76-7.85)$ \\
\hline Strict Protestant & 19.3 & 0.000 & $15.19(4.51-51.19)$ & 4.8 & 0.028 & $4.30(1.17-15.82)$ \\
\hline Roman Catholic & 9.1 & 0.003 & $8.94(2.15-37.22)$ & 0.4 & 0.541 & $1.75(0.29-10.48)$ \\
\hline Evangelical & 3.7 & 0.056 & $5.28(0.96-29.02)$ & 4.2 & 0.040 & 6.35 (1.09-36.93) \\
\hline
\end{tabular}

Note: ${ }^{1} \mathrm{~N}=150 .{ }^{2} \mathrm{~N}=155$. Significant results $(p<0.05)$ are printed in bold.

Current strict Protestant or Evangelical patients had RHs significantly more frequently than the other categories (see the right panel of Table 4). Strict Protestant or Evangelical backgrounds showed interactions only on the level of a statistical trend with the main diagnostic group (schizophrenia or psychotic depression) in the association with RHs. This trend was apparent in patients raised in a strict Protestant church (product term with diagnostic group B = 2.6, SE $=1.3, p=0.055$ ) and patients currently attending an Evangelical church $(\mathrm{B}=1.7, \mathrm{SE}=0.9, p=0.081)$. Stratified analyses show that RHs are significantly more prevalent in raised strict Protestant patients with psychotic depression $\left(\chi^{2}=10.7, \mathrm{df}=4, p=0.030\right)$ than in raised strict Protestant patients with schizophrenia $\left(\chi^{2}=1.7, \mathrm{df}=4\right.$, $p=0.793$ ), but this does not apply to Evangelicals. Analysis of the product terms between the main diagnoses and the other denominations exhibiting associations with RDs or RHs (Roman Catholic, Evangelical) did not show significant interactions.

Regarding the content of RHs, voices attributed to the devil occurred just as often in strict as in moderate Protestant patients (see Table 3). Almost all the moderate Protestant patients with RHs mentioned RHs about God, whereas this was never the case with strict Protestant patients with RHs. 


\subsection{RDs and RHs Linked to the Other Aspects of Religiousness}

As is shown in the left panel of Table 5, other aspects of religiousness such as dogmatism, salience, church attendance, prayer, seeing oneself as a child of God, the positive religious coping subscale, and reading the Bible or other religious texts were statistically significantly associated with a higher prevalence of RDs. In contrast, the negative religious coping subscale was statistically significantly associated with a lower prevalence of RDs.

Table 5. Associations between other aspects of religiousness and RDs and RHs in a sample of 155 patients; results of separate logistic regression analyses for other aspects of religiousness adjusted for effect by gender.

\begin{tabular}{|c|c|c|c|c|c|c|c|c|}
\hline \multirow{2}{*}{$\begin{array}{c}\text { Aspects of } \\
\text { Religiousness }\end{array}$} & \multicolumn{4}{|c|}{ Religious Delusions } & \multicolumn{4}{|c|}{ Religious Hallucinations } \\
\hline & $\mathbf{N}$ & Wald & $p$ & OR $(95 \% \mathrm{CI})$ & $\mathbf{N}$ & Wald & $p$ & OR $(95 \% \mathrm{CI})$ \\
\hline Dogmatism $^{1}$ & 57 & 10.7 & 0.001 & $2.51(0.08-1.56)$ & 89 & 5.2 & 0.023 & $1.32(1.04-1.68)$ \\
\hline Salience $^{2}$ & 83 & 13.4 & 0.000 & $25.0(4.5-140.0)$ & 89 & 7.1 & 0.008 & $9.38(1.81-48.72)$ \\
\hline Church attendance & 125 & 9.0 & 0.003 & $1.17(1.06-1.30)$ & 137 & 1.5 & 0.222 & $1.08(0.96-1.22)$ \\
\hline Praying & 96 & 5.3 & 0.022 & $6.44(1.32-31.54)$ & 96 & 1.2 & 0.273 & $2.43(0.50-11.92)$ \\
\hline Child of God & 80 & 5.7 & 0.017 & $7.11(1.42-35.73)$ & 80 & 3.2 & 0.073 & $7.08(0.83-60.18)$ \\
\hline RCOPE_POS ${ }^{3}$ & 78 & 11.4 & 0.001 & $1.30(1.12-1.52)$ & 85 & 5.4 & 0.020 & $1.23(1.03-1.46)$ \\
\hline RCOPE_NEG ${ }^{4}$ & 86 & 5.0 & 0.025 & $0.74(0.56-0.96)$ & 86 & 1.3 & 0.252 & $0.85(0.64-1.13)$ \\
\hline Reading 5 & 95 & 14.6 & 0.000 & $1.56(1.24-1.97)$ & 95 & 3.3 & 0.069 & $1.19(0.99-1.44)$ \\
\hline
\end{tabular}

Note: ${ }^{1}$ Dogmatism $=$ the level of adherence to traditional Christian religious beliefs assessed by orthodoxy scale, ${ }^{2}$ Salience = subjective importance of faith, ${ }^{3}$ RCOPE_POS = questions about seeking support and experiencing faith in troubled times, ${ }^{4}$ RCOPE_NEG $=$ questions about interpretations of deserved punishment or sense of being abandoned by God, ${ }^{5}$ Reading = frequency of reading the Bible or other religious texts. RCOPE: Religious Coping Scale. Significant results $(p<0.05)$ are printed in bold.

Furthermore, as is shown in the right panel of Table 5, dogmatism, salience, and the positive religious coping subscale were statistically significantly more associated with RHs.

Lastly, the religious profiles of the patients without RDs were examined (see Table 6). Non-church members had statistically significantly more non-RDs than those associated with a religious denomination. Furthermore, patients with other, non-religious delusions scored significantly lower on all religiousness questions compared to the patients with RDs. Finally, a statistical trend was observed for patients without RDs with regard to the RCOPE_NEG subscale.

Table 6. Associations between the aspects of religiousness and RDs compared to the aspects of religiousness and other, non-religious delusions in a sample of 155 patients, results from bivariate analyses.

\begin{tabular}{|c|c|c|c|c|c|c|c|}
\hline $\begin{array}{l}\text { Religious } \\
\text { Affiliation }\end{array}$ & $\begin{array}{c}\text { Other, } \\
\text { Non-Religious } \\
\text { Delusions } \\
(\mathrm{N}=106)\end{array}$ & $\begin{array}{c}\text { Religious } \\
\text { Delusions } \\
(\mathrm{N}=49)\end{array}$ & Chi $^{2}$ Test & $\begin{array}{c}\text { Other, } \\
\text { Non-Religious } \\
\text { Delusions } \\
(\mathrm{N}=106)\end{array}$ & $\begin{array}{c}\text { Religious } \\
\text { Delusions } \\
(\mathrm{N}=49)\end{array}$ & $t$-Test & Sign \\
\hline & $\%$ & $\%$ & $\chi^{2}(\mathrm{df})$ & mean & mean & $\mathbf{t}$ & $p$ \\
\hline \multicolumn{8}{|c|}{ Religious affiliation } \\
\hline Moderate & 39.6 & 28.6 & - & - & - & - & - \\
\hline Protestants & - & - & - & - & - & - & - \\
\hline Strict protestants & 10.4 & 36.7 & - & - & - & - & - \\
\hline Roman Catholic & 5.7 & 14.3 & - & - & - & - & - \\
\hline
\end{tabular}


Table 6. Cont.

\begin{tabular}{|c|c|c|c|c|c|c|c|}
\hline $\begin{array}{l}\text { Religious } \\
\text { Affiliation }\end{array}$ & $\begin{array}{c}\text { Other, } \\
\text { Non-Religious } \\
\text { Delusions } \\
(\mathrm{N}=106)\end{array}$ & $\begin{array}{c}\text { Religious } \\
\text { Delusions } \\
(\mathrm{N}=49)\end{array}$ & Chi $^{2}$ Test & $\begin{array}{c}\text { Other, } \\
\text { Non-Religious } \\
\text { Delusions } \\
(\mathrm{N}=106)\end{array}$ & $\begin{array}{c}\text { Religious } \\
\text { Delusions } \\
(\mathrm{N}=49)\end{array}$ & $t$-Test & Sign \\
\hline & $\%$ & $\%$ & $\chi^{2}(\mathrm{df})$ & mean & mean & $\mathbf{t}$ & $p$ \\
\hline \multicolumn{8}{|c|}{ Other religious variables } \\
\hline Salience $^{2}$ & 35.8 & 86.4 & $16.9(\mathrm{df1})$ & - & - & - & 0.000 \\
\hline Church attendance & 30.6 & 80.0 & $18.5(\mathrm{df} 1)$ & - & - & - & 0.000 \\
\hline Praying & 69.0 & 92.0 & $5.2(\mathrm{df} 1)$ & - & - & - & 0.022 \\
\hline Child of God ${ }^{3}$ & 59.0 & 89.5 & $6.0(\mathrm{df} 1)$ & - & - & - & 0.014 \\
\hline
\end{tabular}

Note: ${ }^{1}$ Dogmatism $=$ the level of adherence to traditional Christian religious beliefs assessed by orthodoxy scale, ${ }^{2}$ Salience $=$ subjective importance of faith, ${ }^{3}$ Child of God $=$ seeing oneself as a child of God or sometimes as a child of God, ${ }^{4}$ Reading $=$ frequency of reading the Bible or other religious texts, ${ }^{5}$ RCOPE_POS $=$ questions about seeking support and experiencing faith in troubled times, ${ }^{6}$ RCOPE_NEG = questions about interpretations of deserved punishment or sense of being abandoned by God. Significant results $(p<0.05)$ are printed in bold.

\section{Discussion}

Our study aimed to describe (1) the frequency and content of RHs in older mental health care patients diagnosed with affective or non-affective psychotic disorders, (2) the relation between RDs and RHs and the main diagnosis, and (3) how RDs and RHs relate to denominational background, whether possible associations are related to the main diagnosis (affective vs. non-affective psychosis), and (4) how RDs and RHs are linked to other aspects of religiousness.

As to the first research question, RHs were fairly common in older patients in geriatric psychiatry when suffering from a psychotic disorder (19\%). Twenty-two of the patients with RHs had auditory RHs $(14 \%)$ and nine had visual RHs $(6 \%)$. The results were in the prevalence range as reported by Cook (2015) in his review.

The second research question pertained to how RDs and RHs related to the main diagnosis. As was noted in Noort et al. (2018), RDs were common in older adults with schizophrenia and psychotic depression. In schizophrenia patients, the prevalence of $20-44 \%$ was quite similar to previous research results (Raja et al. 2000; Appelbaum et al. 1999; Azhar et al. 1993). However, in patients with psychotic depression, the present data showed a prevalence of $47 \%$, thus much higher than the $14 \%$ in the study by Appelbaum.

Only a few studies on RHs have been conducted in schizophrenia patients, with prevalences ranging from 2 to 53\% for auditory RHs (Cook 2015). Unfortunately, the possible influence of the type of disorder was not examined in Atallah et al. (2001) in a mixed group of affective and non-affective psychotic patients, and was only linked to a changing religious and political climate. Ouwehand et al. (2019) demonstrated a variation in the prevalences of RDs as well as RHs during bipolar disorder episodes.

Although the detailed results on the content of RHs pertain to low numbers and are solely useful as illustrations, RHs featuring the devil or Satan occurred more frequently in patients with psychotic depression than in those with schizophrenia. Sixty-six percent of the psychotic depressive patients had a delusion of guilt (Noort et al. 2018), suggesting a mood disorder due to an extremely depressed mood. Delusions of guilt may also explain the content of RHs about the devil.

As to the third research question, RDs were significantly more prevalent in raised and current strict Protestants and Roman Catholics. Religion, in particular strict Protestantism, can be seen as a symptom-formation factor for RDs. Moreover, stratified analyses showed that RDs were significantly more prevalent in psychotic depressive patients who were raised or current strict Protestants. The sentence 
has been changed as follows (line 409-12): In Roman Catholics and Evangelicals (e.g., Pentecostals), the same pattern appears to be emerging as in strict Protestants. If the numbers of Roman Catholic patients and Evangelical patients would have been larger, similar statistically significant patterns may have been demonstrated. Furthermore, RHs were more prevalent in raised strict Protestant patients with a psychotic depression. Religion, in particular strict Protestantism, can also be seen as a symptom-formation factor for RHs. Moreover, the content of almost all the RHs in strict Protestant patients was punitive, and none of the strict Protestant patients heard the voice of God or Jesus. As is noted in the Introduction, a strong dogmatic or rational approach to belief with an emphasis on an inner experience (devotion), and a high percentage of delusions of guilt seemed to contribute to RDs and RHs more frequently in strict Protestant patients with psychotic depression. RHs were also more prevalent in current Evangelical patients. However, no difference was found as regards the main diagnoses.

As to the fourth research question on other aspects of religiousness, patients with RDs had significantly higher scores on most aspects of religiousness than patients with other delusions in the sample (Table 5). Rudalevičienè et al. (Rudalevičienè et al. 2008) demonstrated that the subjective importance of religion was significantly related to the presence of RDs, and religious practices have been associated with a higher rate of RDs (Peters et al. 1999; Atallah et al. 2001). In individuals diagnosed with a persistent mental illness $(\mathrm{N}=406$, mean age $=41, \mathrm{SD} \pm 11)$ (Tepper et al. 2001), 48\% indicated that religion became more important to them when their symptoms worsened. Religious activity may provide a sense of control and meaning with a perspective beyond oneself (Pargament 1996) and may serve as a pervasive and potentially effective method of coping with mental illness (Tepper et al. 2001).

As is noted by Rieben et al. (2013) and Mohr et al. (2009), several processes probably play a role in the formation of delusions. In affective psychosis, a severely disturbed mood may require a religious explanation. As a result, individual religious cognitive schemas can be recruited, ultimately resulting in the formation of RDs. At the same time, negative cognitive schemas can also be activated. Doubt about God's faithfulness, God's love or indeed God's very existence can increase fear and perhaps advance guilt delusions. Anger at God might well recruit a mechanism of distancing from God. This can explain why the negative religious coping subscale is related to lower prevalences of RDs.

As to other aspects of religiousness and $\mathrm{RHs}$, evangelical Christianity bears similarities to dogmatic Protestantism, where the personal experience of redemption through Jesus Christ is central. High scores on salience (subjective importance of faith) and the positive religious coping subscale (questions about seeking support and experiencing faith in troubled times) are in keeping with these religious traditions.

Finally, regarding the religious profiles of those who do not have RDs, the question may arise as to whether atheism protects against RDs. We cannot say that based on our research. Fourteen percent of the non-church members still had RDs. Furthermore, patients without RDs scored significantly lower on most religion features, but not zero. Finally, it is striking that patients without RDs score higher on the negative religious coping subscale. So we also cannot say that patients without RDs are atheist.

One limitation of our study pertains to the participation rate: Sixty-three percent was somewhat less than what would have been feasible with an entirely consecutive sample. No data were obtained from patients who refused to participate or who were not identified by their clinicians as meeting the criteria. This is why no plausible reasons were recorded for non-participation due to refusal, physical frailty or communication problems accompanying an excessively severe psychotic state. There can be another limitation if the SCAN does not specifically identify RHs and scoring can only be done after the interview based on the researcher's notes. Furthermore, the low numbers of those with a manic psychotic episode meant that no separate calculations could be made for this category. Moreover, strict protestants can be identified in certain, more rural regions in the Netherlands, but do not have large communities in more urban regions. However, there seem to be some parallels with other types of fairly orthodox Christian movements (Evangelicals—which are perceived as "Protestants," but not "Calvinists or Lutherans"), such as the Pentecostal communities. However, more research is needed to replicate findings in Pentecostal communities. Furthermore, the relatively low number of Roman Catholic and Evangelical (e.g., Pentecostal) patients makes it impossible to identify mechanisms that 
can lead to psychopathological symptoms, as have now been observed in strict Protestants. Finally, although a wide range of measures on religiousness was applied, no questionnaires were included that touched on the transcendent aspects of faith (e.g., God image) or on the concept of spirituality. Future psychiatric epidemiological studies on RDs and RHs could benefit from the research experience in the field of the psychology of religion and empirical theology.

\section{Conclusions}

Our study examined the prevalence and content of RHs, how RDs and RHs are related to the main diagnosis, whether possible associations are related to the main diagnosis (affective or non-affective psychoses), and how RDs and RHs are linked to denominational background and other aspects of religiousness.

Nineteen percent of the patients had RHs in all the modalities. The content of the RHs mainly pertained to the devil and God. There was no statistically significant difference between RDs and RHs in schizophrenic patients and those with psychotic depression. RDs in raised and current strict Protestant patients were significantly more prevalent in those with psychotic depression than in those with schizophrenia. Compared to the other denominational groups, RHs in raised strict Protestant patients were significantly more prevalent in patients with psychotic depression than in those with schizophrenia. The strict Protestant patients with RHs never heard voices they attributed to God. The significantly higher scores on almost all aspects of religion in patients with RDs may indicate that religious activity provides a sense of control and meaning when dealing with psychiatric disorders.

As religion represents an important cultural resource for older adults, it is hypothesized that, in particular, the strict Protestant faith represents a symptom-formation factor for RDs and RHs in the older generation. It is plausible that, as opposed to younger generations, older adults still primarily articulate their depression as a religious or physical problem. They even may experience sadness and anhedonia as a positive sign and not a negative one: rather than to complain, they prefer "to carry on and pray for strength." The assumption is that psychotic anguish due to RHs (usually the devil) is a psychological protection mechanism given the content of RDs. The confusing experience can confirm the predestination doctrine that man has no influence on being born again or receiving eternal life. Paradoxically, this lifelong doubt can provide anxiety reduction in a psychotic depressed state. It would be wise to further evaluate this area of religious coping. Further research should be conducted into the relation between the duration of the disease and whether there was a long delay before treatment began for RDs.

There should be a certain sensitivity to how patients formulate religious themes, because, otherwise, information may be missed or misinterpreted. It is also important for mental health professionals to be able to distinguish between "normal" religious experiences and phenomena symptomatic of mental disorders (Demling 2016). More carefully focused research might elicit a fuller understanding of patients' beliefs and experiences. This might help patients feel more fully understood and, if handled sensitively, it could help build trust. This is why religion and other sub-cultural fields should be included in the training curriculum. Moreover, this knowledge should be further evaluated from an intercultural perspective; denominational differences can be understood as intercultural differences.

We hope that a better understanding of the relation of religion to various aspects of psychopathology will lead to deeper insight into patients by clinicians and better therapeutic outcomes for the patients.

Author Contributions: Conceptualization, A.N.; formal analysis, A.W.B.; methodology, A.T.F.B. All authors have read and agreed to the published version of the manuscript.

Funding: This research received no external funding.

Acknowledgments: The data were collected with the support of Yulius Mental Health Care, Gorinchem/Dordrecht, the Netherlands. The authors would like to thank staff members of the Department of Old Age Psychiatry at Yulius Mental Health Care for their assistance.

Conflicts of Interest: The authors declare no conflict of interest. 


\section{References}

Akiskal, Hagop S. 2017. Mood disorders: Clinical features. In Kaplan E Sadock's Comprehensive Textbook of Psychiatry, 10th ed. Philadelphia: Wolters Kluwer Health, p. 1637. ISBN 9781451100471.

American Psychiatric Association (APA). 2000. Diagnostic and Statistical Manual of Mental Disorders, 4th ed. Washington, DC: American Psychiatric Association, ISBN 0890420254.

Appelbaum, Paul S., Pamela Clark Robbins, and Loren H. Roth. 1999. Dimensional approach to delusions: Comparison across types and diagnoses. American Journal of Psychiatry 156: 1938-43. [CrossRef]

Atallah, Sherif F., Ahmed R. El-Dosoky, E. M. Coker, K. M. Nabil, and M. Fakhr El-Islam. 2001. A 22-year retrospective analysis of the changing frequency and patterns of religious symptoms among inpatients with psychotic illness. Social Psychiatry and Psychiatric Epidemiology 36: 407-15. [CrossRef] [PubMed]

Azhar, M. Zain, S. L. Varna, and H. R. Hakim. 1993. Phenomenological differences of hallucinations between schizophrenic patients in Penang \& Kelantan. Medical Journal of Malaysia 48: 146-52. [PubMed]

Bauer, Susanne M., Hans Schanda, Hanna Karakula, Luiza Olajossy-Hilkerberger, Palmira Rudaleviciene, Nico Okribelashvili, Haroon R. Chaudhery, Sunday E. Idemudia, Sharon Gscheider, Kristina Ritte, and et al. 2011. Culture and the prevalence of hallucinations in schizophrenia. Comprehensive Psychiatry 52: 319-25. [CrossRef] [PubMed]

Becker, J. W., and R. Vink. 1994. Secularisatie in Nederland, 1966-1991; de Verandering van Opvattingen en Enkele Gedragingen [Secularization in the Netherlands, 1966-1991; The Change of Views and Some Behaviours]. The Hague: VUGA, ISBN 9052506086.

Braam, Arjan W., Aartjan T. F. Beekman, Dorly J. Deeg, Jan W. Smit, and Willem van Tilburg. 1997. Religiosity as a protective or prognostic factor of depression in late life; results from a community survey in the Netherlands. Acta Psychiatrica Scandinavia 96: 199-205. [CrossRef] [PubMed]

Braam, Arjan W., Aartjan T. F. Beekman, Pieter van den Eeden, Dorly J. Deeg, Kees P. Knipscheer, and Willem van Tilburg. 1999. Religious climate and geographical distribution of depressive symptoms in older Dutch citizens. Journal of Affective Disorders 54: 149-59. [CrossRef]

Braam, Arjan W., Hanneke Schaap-Jonker, Bianca Mooi, Dineke de Ritter, Aartjan T. F. Beekman, and Dorly D. H. Deeg. 2008. God image and mood in old age; results from a community-based pilot study in the Netherlands. Mental Health, Religion and Culture 11: 221-37. [CrossRef]

Braam, Arjan W., Pieter van den Eeden, Martin Prince, and Aartjan T. F. Beekman. 2001. Religion as a cross-cultural determinant of depression in elderly Europeans: Results from the EURODEP collaboration. Psychological Medicine 31: 803-14. [CrossRef]

Chaudhury, Suprakash. 2010. Hallucinations: Clinical aspects and management. Industrial Psychiatry Journal 19: 5-12. [CrossRef]

Cook, Christopher C. H. 2015. Religious psychopathology: The prevalence of religious content of delusions and hallucinations in mental disorder. International Journal of Social Psychiatry 61: 404-25. [CrossRef]

De Jong, Gert. 2012. Religieuze kaart van Nederland [A religious map of the Netherlands]. In Handboek Psychiatrie, Religie en Spiritualiteit. [Manual of Psychiatry, Religion and Spirituality]. Edited by Peter J. Verhagen and Harold J. G. M. van Megen. Utrecht: De Tijdstroom, pp. 96-99. ISBN 9789058981943.

De Lely, Arie Jan A., Walter W. Van den Broek, Paul G. H. Mulder, and Tom K. Birkenhäger. 2009. Symptomen bij een depressie; bevindelijk gereformeerde versus niet-kerkelijke patiënten. [ Symptoms in depression; Orthodox Reformed versus secular patients]. Tijdschrift voor Psychiatrie 51: 279-89. [PubMed]

Demling, Joachim Heinrich. 2016. Gesunde Religiosität oder religiöser Wahn? [Healthy religiosity or religious delusion?]. DNP-Der Neurologe \& Psychiater 17: 45-53.

Folstein, Marshal F., Susan E. Folstein, and Paul R. McHugh. 1975. "Mini-mental state": A practical method for the clinician. Journal of Psychiatric Research 12: 189-98. [CrossRef]

Galleti, Chiara, Enrico Paolini, Alfonso Tortorella, and Michael T. Compton. 2017. Auditory and non-auditory hallucinations in first-episode psychosis: Differential associations with diverse clinical features. Psychiatry Research 254: 268-74. [CrossRef] [PubMed]

Gecici, Omer, Murat Kuloglu, Ozkan Guler, Omer Ozbulut, Erhan Kunrt, Sinay Onen, Okan Ekinci, Dilek Yesilbas, Ali Caykoylu, Murat Emül, and et al. 2010. Phenomenology of delusions and hallucinations in patients with schizophrenia. Bulletin of Clinical Psychopharmacology 20: 204-12. [CrossRef]

Giel, Rob, and Fokko J. Nienhuis. 2001. Schedules for Clinical Assessment in Neuropsychiatry, SCAN 2.1. Lisse: Harcourt. 
Grover, Sandeep, Triveni Davuluri, and Subho Chakrabarti. 2014. Religion, spirituality, and schizophrenia: A review. Indian Journal of Psychological Medicine 36: 119-24. [CrossRef]

Hijweege, Nicolette. 2004. Bekering in Bevindelijk Gereformeerde Kring. Een Psychologische Studie. [Conversion in Orthodox Dutch Reformed Circle. A Psychological Study]. Kampen: Kok, pp. 89-98. ISBN 9043509957.

Hoekstra, E. G., and M. H. Ipenburg. 1995. Wegwijs in Religieus en Levensbeschouwelijk Nederland. Handboek Religies, Kerken, Stromingen en Organisaties [Guide to Religions and Beliefs in The Netherlands. Manual on Religions, Churches, Denominations and Organisations]. Kampen: Kok, p. 360. ISBN 9789024282470.

Hoge, D. R., and Ernesto de Zulueta. 1985. Salience as a condition for various social consequences of religious commitment. Journal for the Scientific Study of Religion 24: 21-38. [CrossRef]

Kent, Gerry, and Saeed Wahass. 1996. The content and characteristics of auditory hallucinations in Saudi Arabia and the UK: A cross-cultural comparison. Acta Psychiatrica Scandinavia 94: 433-37. [CrossRef]

Lewis, Stephan F., Rodrigo Escalona, and Samuel J. Keith. 2017. Phenomenology of schizophrenia. In Kaplan $\mathcal{E}$ Sadock's Comprehensive Textbook of Psychiatry, 10th ed. Edited by B. J. Sadock, V. A. Sadock and P. Ruiz. Philadelphia: Wolters Kluwer Health, p. 1415. ISBN 9781451100471.

Lim, Anastasia, Hans W. Hoek, Mathijs L. Deen, and Jan Dirk Blom. 2016. Prevalence and classification of hallucinations in multiple sensory modalities in schizophrenia spectrum disorders. Schizophrenia Research 176: 493-99. [CrossRef]

Mbewe, Eddie, Alan Haworth, Joy Welham, Didduh Mubanga, Roy Chazulwa, Mary M. Zulu, John Mayeya, and John J. McGrath. 2006. Clinical and demographic features of treated first-episode psychotic disorders: A Zambian study. Schizophrenia Research 86: 202-7. [CrossRef]

Mohr, Sylvia, Samuel Pfeifer, Philippe Huguelet, and Harold G. Koenig. 2009. Delusions and hallucinations with religious content. In Religion and Spirituality in Psychiatry. Edited by Huguelet Philippe and Harold G. Koenig. New York: Cambridge University Press, pp. 81-96. ISBN 9780521889520.

Noort, Annemarie, Aartjan T. F. Beekman, Arthur R. van Gool, and Arjan W. Braam. 2018. Religious delusions in older adults: Diagnosis, combinations, and delusional characteristics. International Journal of Geriatric Psychiatry 33: 1680-87. [CrossRef] [PubMed]

Okutate, Gbenga T., and O. B. E. Jones. 2003. Auditory hallucinations in schizophrenic and affective disorder Nigerian patents: Phenomenological comparison. Transcultural Psychiatry 40: 531-41. [CrossRef] [PubMed]

Ouwehand, Eva, Arjan W. Braam, Jan Willem Renes, Hanneke Muthert, Hanne A. Stolp, Heike H. Garritsen, and Hetty Zock. 2019. Prevalence of religious and spiritual experiences and the perceivedinfluence thereof in patients with bipolar disorder in a Dutch specialist outpatient center. Journal of Nervous and Mental Disorders 207: 291-99. [CrossRef] [PubMed]

Oyebode, Femi. 2018. Sims' Symptoms in the Mind. Textbook of Descriptive Psychopathology, 6th ed. Edinburgh: Elsevier, p. 115. ISBN 9780702074011.

Pargament, Kenneth I. 1996. Religious methods of coping: Resources for the conservation and transformation of significance. In Religion and the Clinical Practice of Psychology. Washington, DC: Shafranske American Psychological Association, pp. 483-509.

Pargament, Kenneth I., and Harold G. Koenig. 2000. The many methods of religious coping: Development and initial validation of the RCOPE. Journal of Clinical Psychology 56: 519-543. [CrossRef]

Peralta, Victor, and Manuel J. Cuesta. 1999. Dimensional structure of psychotic symptoms: An item-level analysis of SAPS and SANS symptoms in psychotic disorders. Schizophrenia Research 38: 13-26. [CrossRef]

Peters, Emmanuelle, Samantha Day, Jacqueline McKenna, and Gilli Orbach. 1999. The incidence of delusional ideation in religious and psychotic populations. British Journal of Clinical Psychology 38: 83-96. [CrossRef]

Raja, Michelle, Antonella Azzoni, and Loredana Lubich. 2000. Religious delusion: An observational study of religious delusion in a population of 313 acute psychiatric inpatients. Schweizer Archiv für Neurologie, Neurochirurgie at de Psychiatrie 51: 22-29.

Rajapakse, Thilini, Alexandra Garcia-Rosales, Saman Weerawardene, Sue Cotton, and Richard Fraser. 2011. Themes of delusions and hallucinations in first-episode psychosis. Early Intervention in Psychiatry 5: 254-58. [CrossRef]

Rieben, Isabelle, Sylvia Mohr, Laurence Borras, Christiane Gillieron, Pierre-Yves Brandt, Nader Perroud, and Philippe Huguelet. 2013. A thematic analysis of delusion with religious contents in schizophrenia. The Journal of Nervous and Mental Disease 201: 665-73. [CrossRef] 
Rudalevičienė, Palmira, Thomas Stompe, Andrius Narbekovas, Nijole Raslauskiene, and Robertas Bunevicius. 2008. Are religious delusions related to religiousness in schizophrenia? Medicina (Kaunas) 44: 529-35. [CrossRef]

Tepper, Leslie, Steven A. Rogers, Esther M. Coleman, and H. Newton Malony. 2001. The prevalence of religious coping among persons with persistent mental illness. Psychiatric Services 52: 660-65. [CrossRef] [PubMed]

Thomas, Pramod, Priya Mathur, Irving I. Gottesman, Rajesh Nagpal, Vishwajit L. Nimgaonkar, D. Phil, and Smita N. Deshpande. 2007. Correlates of hallucinations in schizophrenia: A cross-cultural evaluation. Schizophrenia Research 92: 41-49. [CrossRef] [PubMed]

Waters, Flavie, Daniel Collerton, Dominic H. Ffytche, Renaud Jardri, Delphine Pins, Robert Dudley, Jan Dirk Blom, Urs Peter Mosimann, Frank Eperjesi, Stephan Ford, and et al. 2014. Visual hallucinations in the psychosis spectrum and comparative information from neurodegenerative disorders and eye disease. Schizophrenia Bulletin 40: S233-S245. [CrossRef] [PubMed]

Wing, John Kenneth, Thomas Babor, Terry S. Brugha, J. Burke, John E. Cooper, Rob Giel, Assen Jablenski, Darrel Regier, and Norman Sartorius. 1989. SCAN. Schedules for clinical assessment in neuropsychiatry. Archives of General Psychiatry 47: 589-93. [CrossRef]

(C) 2020 by the authors. Licensee MDPI, Basel, Switzerland. This article is an open access article distributed under the terms and conditions of the Creative Commons Attribution (CC BY) license (http://creativecommons.org/licenses/by/4.0/). 